\title{
Developing a Real-Time PCR Assay for Detection and Quantification of Pratylenchus neglectus in Soil
}

Guiping Yan and Richard W. Smiley, Oregon State University, Columbia Basin Agricultural Research Center, Pendleton 97801; Patricia A. Okubara, United States Department of Agriculture-Agricultural Research Service (USDA-ARS), Root Disease and Biological Control Research Unit, Pullman, WA 99164-6430; Andrea M. Skantar, USDA-ARS, Nematology Laboratory, Beltsville, MD 20705; and Catherine L. Reardon, USDA-ARS, Columbia Plateau Conservation Research Center, Pendleton, OR 97801

\begin{abstract}
Yan, G. P., Smiley, R. W., Okubara, P. A., Skantar, A. M., and Reardon, C. L. 2013. Developing a real-time PCR assay for detection and quantification of Pratylenchus neglectus in soil. Plant Dis. 97:757-764.

Pratylenchus neglectus is one of the most widespread and economically important nematodes that invades plant roots and restricts wheat productivity in the Pacific Northwest. It is challenging to quantify $P$. neglectus using microscopic methods for studies that require largescale sampling, such as assessment of rotation crops, wheat cultivars, and other management practices. A real-time quantitative polymerase chain reaction (qPCR) assay was developed to detect and quantify $P$. neglectus from DNA extracts of soil. The primers, designed from the internal transcribed spacer region of rDNA, showed high specificity with a single melt curve peak to DNA from eight isolates of $P$. neglec-

and non-plant-parasitic nematodes. A standard curve $\left(R^{2}=0.96 ; P<\right.$ 0.001 ) was generated by amplifying DNA extracted from soil to which nematodes were added. The soil standard curve was validated using sterilized soil inoculated with lower numbers of $P$. neglectus. A significant positive relationship $\left(R^{2}=0.66 ; P<0.001\right)$ was observed for nematode numbers quantified from 15 field soils using qPCR and the Whitehead tray and microscopic method but the qPCR generally tended to provide higher estimates. Real-time PCR potentially provides a useful platform for efficient detection and quantification of $P$. neglectus directly from field soils.
\end{abstract} tus but did not amplify DNA from 28 isolates of other plant-parasitic
Pratylenchus neglectus is one of the most important root-lesion nematodes that invades roots of plants and restricts productivity of wheat in the Pacific Northwest (PNW) $(28,30,32,34)$. This nematode has been detected in $95 \%$ of dryland wheat-producing fields surveyed in Idaho, Oregon, and Washington $(32,35)$ and in $40 \%$ of fields in Montana (14). P. neglectus was more widely distributed than $P$. thornei, another damaging root-lesion nematode species in the PNW, but mixed populations also occurred (32). Population density of $P$. neglectus at preplanting has often been inversely correlated with wheat grain yield $(32,33)$ and yield reductions were generally 8 to $36 \%$ for susceptible spring wheat cultivars in Oregon (34). P. neglectus together with $P$. thornei were estimated to reduce farm profits by about $\$ 51$ million annually in the three PNW states $(28,29)$. Multiple factors such as variable climate and weather, host genotype, nematode virulence, and cropping system make it difficult to determine economic damage thresholds for Pratylenchus spp. (33). However, an initial population of 2,000 P. neglectus per kilogram of soil reduced wheat grain yield in one dryland and one irrigated field experiment in Oregon (34). Potentially damaging high populations have been detected in up to $60 \%$ of the wheat fields sampled in the PNW (29).

Management of lesion nematodes at high population densities is best approached by integrating crop rotation and use of resistant and tolerant wheat cultivars $(29,33,37)$. To some extent, crop rotation alone is limited because $P$. neglectus is polyphagous and has a broad range of hosts such as legumes, cereals, biofuel crops, and many other genera of broadleaf and grass weeds $(5,29,33,39)$. Minimizing damage by crop rotation is possible only if resistant or tolerant rotation crops are available and profitable for growers.

Corresponding author: G. P. Yan, E-mail: guiping.yan@oregonstate.edu

Accepted for publication 30 December 2012.

http://dx.doi.org/10.1094/PDIS-08-12-0729-RE

(C) 2013 The American Phytopathological Society
However, many crops differed in susceptibility to each Pratylenchus spp. (33,39), and these differences were also observed at the cultivar level. For instance, a wheat cultivar with resistance or tolerance to $P$. neglectus was not necessarily resistant or tolerant to $P$. thornei, and vice versa (28). Therefore, nematode species identification and quantification are essential for selecting the bestperforming rotation crops and wheat cultivars for optimal disease management.

Distinguishing P. neglectus from P. thornei and other closely related Pratylenchus spp. using traditional microscopic methods is based on subtle morphological differences in lip annule number, tail shape, and vulva position $(6,10)$. This process is time-consuming and it is difficult to count and identify these species from large numbers of field soil samples, especially when other nematodes are present.

Commercial laboratories provide nematode diagnostic services and routinely report total numbers of lesion nematodes at the genus level but do not identify and quantify them to the species level. DNA-based technologies provide a rapid alternative to microscopic methods. A commercial laboratory, South Australia Research and Development Institute (SARDI, Adelaide, Australia), provides a comprehensive DNA-based testing service for quantification of $P$. neglectus along with two other nematode pathogens and six fungal pathogens of wheat $(12,20,23)$. However, their protocols are proprietary. There is a demand for a publically available quantitative polymerase chain reaction ( $\mathrm{qPCR}$ ) procedure for quantitative testing of $P$. neglectus in soil, combined with identification to species level. At least one PNW commercial laboratory has an expert nematode diagnostician, and possesses qPCR capabilities for fungal crop pathogens but lacks the option for qPCR diagnosis of nematodes such as $P$. neglectus in soil samples (http://www. westernlaboratories.com)

A number of PCR-based methods have been developed for differentiating species of plant-parasitic nematodes (19). PCR in combination with restriction fragment length polymorphism was used to differentiate Pratylenchus spp. $(21,36,40)$. One-step species-specific PCR followed by gel electrophoresis was performed for discrimination of six Pratylenchus spp., including P. neglectus 
and $P$. thornei (1). Carrasco-Ballesteros et al. (4) identified $P$. thor$n e i$ based on a randomly amplified polymorphic DNA (RAPD) fragment and sequence-characterized amplified region primers designed from the unique RAPD fragment. Yan et al. (44) developed a species-specific PCR assay to detect and identify P. neglectus and P. thornei from soil using primers from the Pratylenchus D3 expansion domains of the 28S rRNA gene. This method separated $P$. neglectus from $P$. thornei based on amplicon sizes of 144 and $288 \mathrm{bp}$, respectively, and did not amplify other nematodes commonly present in PNW wheat fields. However, the abovementioned endpoint PCR methods are not suitable for quantification. A rapid and sensitive qPCR method is needed for quantification of $P$. neglectus from soil. Berry et al. (2) utilized a SYBR Green I-based qPCR assay for detection and quantification of the lesion nematode $P$. zeae, root-knot nematode Meloidogyne javanica, and dagger nematode Xiphinema elongatum. Sato et al. $(25,26)$ reported a rapid and precise qPCR method for $P$. penetrans in a nematode community and in soil. Qiu et al. (22) briefly reported a qPCR method for $P$. vulnus. Yan et al. (43) developed a real-time PCR method for quantification of $P$. thornei from DNA extracts of soil using primers designed from the internal transcribed spacer region (ITS) of rDNA. However, there are no published reports describing a qPCR procedure for $P$. neglectus.

The objectives of this study were to develop a qPCR assay for detection and quantification of $P$. neglectus directly from DNA extracts of soil, and to determine whether the assay was applicable to natural field soils harboring this nematode at a range of population densities.

\section{Materials and Methods}

Extraction of DNA from pure culture and soil. Root-lesion nematodes ( $P$. neglectus and $P$. thornei) were isolated from soilfree, carrot-based cultures maintained at $22^{\circ} \mathrm{C}$ in an incubator (43). $P$. neglectus and $P$. thornei were identified based on vulva position (76 to $87 \%$ for P. neglectus and 73 to $80 \%$ for $P$. thornei), tail morphology (pointed but still round for $P$. neglectus and slightly truncated for $P$. thornei), and lip annule number (two for $P$. neglectus and three for $P$. thornei) $(6,10)$. Species identity was confirmed by performing endpoint PCR (44). Total DNA was extracted from nematodes following the protocol described by Yan et al. (44) using a lysis buffer containing $500 \mathrm{mM} \mathrm{KCl}, 100 \mathrm{mM}$ Tris- $\mathrm{Cl}(\mathrm{pH}$ 8.3), $15 \mathrm{mM} \mathrm{MgCl}_{2}, 10 \mathrm{mM}$ dithiothreitol (DTT), $4.5 \%$ Tween 20 , and $0.1 \%$ gelatin. Total DNA was extracted from artificially infested soils and naturally infested field soils using the PowerSoil DNA Isolation Kit (MoBio) and the MO BIO Vortex Adapter tube holder according to the manufacturer's recommendations, with one modification: use of 0.5 rather than $0.25 \mathrm{~g}$ of soil for each extract. DNA concentrations were determined using the NanoDrop ND1000 Spectrophotometer. DNA was stored at $-20^{\circ} \mathrm{C}$ prior to qPCR.

Design of primers. An alignment of $P$. neglectus and $P$. thornei ribosomal DNA sequences was made using ClustalW (15) and 24 accessions obtained from GenBank (FJ712956, FJ712952, FJ712953, FR692298, FR692293, FR692290, FR692288, FR692278, FR692283, HM469449, FJ717819, FR692296, FR692295, and FJ717818 for P. neglectus; FJ713003, FJ713006, FJ713002, FJ713004, FR692305, FR692303, FR692304, FR692302, FJ717820, and FJ717821 for P. thornei). Seven primer pairs were designed from conserved sequences within the ITS regions of $P$. neglectus nuclear ribosomal RNA genes. The primers occurred in regions that were divergent from the $P$. thornei sequences. Annealing temperature, GC content, and potential for self duplex formation was predicted for each primer using GeneRunner (version 3.05; Hastings Software, Inc.), and potential primer dimer formation using OLIGO 4.0 (24). Primers were synthesized and cartridge-purified by Invitrogen Corp. Each primer pair was evaluated on the basis of target specificity, amplification efficiency, endpoint fluorescence, and melting curve profile. Amplification efficiency (E) was calculated from the slope of a plot of cycle threshold $(\mathrm{Ct})$ (y-axis) and log picograms (log pg) of DNA (x-axis) using the equation $\mathrm{E}=10^{(1 /-\mathrm{m})}-1$, where $m$ is the slope (7). The forward primer Pn-ITS-F2 (5'-GGCACTGTGCGAAGTGTCCG$\left.3^{\prime}\right)$ and the reverse primer Pn-ITS-R2 (5'-TTAACACCTCAG GCGTCATGTAC-3') produced a deduced amplicon that was 234 bp in length and was used for all the experiments.

Specificity of primers. The primers were screened for target specificity using DNA from eight isolates of $P$. neglectus from Oregon, Washington, Idaho, and Montana (Table 1). Non-target DNA (Table 1) was obtained from extracts of three isolates of $P$. thornei from Oregon, and 25 isolates of other nematodes, including five Pratylenchus spp. (P. agilis, $P$. crenatus, $P$. penetrans, $P$. scribneri, and $P$. zeae), three Meloidogyne spp. (M. hapla, M. chitwoodi, and $M$. naasi), two Heterodera spp. (Heterodera avenae and $H$. filipjevi), seven other plant-parasitic nematode species, and two non-plant-parasitic nematode communities typically present in PNW dryland wheat fields.

An in silico analysis was performed to expand the specificity evaluation for additional Pratylenchus spp. and isolates that could not be obtained in culture or in the form of DNA upon request. In all, 36 ITS sequences of 24 Pratylenchus spp. from the United States and 13 other countries were acquired from GenBank and analyzed for primer-template duplex stability using the computer software PrimerSelect 5.00 (DNASTAR, Inc.) $(18,27,43,44)$. The Pratylenchus spp. were $P$. neglectus (FJ712952, FJ712955, FJ717818, FR692282, FR692284, and FR692297), P. thornei (FJ713002, FJ713005, FJ717820, FJ717821, FR692299, and FR692302), P. agilis (FJ712891), P. bolivianus (FR692329), $P$. brachyurus (HQ662583), P. coffeae (AY561436), P. convallariae (FJ712910), P. crenatus (FJ712916), P. fallax (FJ712918), P. floridensis (GQ988375), P. goodeyi (FR692324), $P$. gutierrezi (FR692277), $\quad P . \quad$ hippeastri (FN554888), $P$. hispaniensis (FJ717816), P. jaehni (FJ712941), P. lentis (AM933152), P. loosi (JN091968), $P$. mediterraneus (FR692315), P. parafloridensis (GQ988378), P. penetrans (FJ712961 and FJ712969), P. pinguicaudatus (FJ712996), P. pseudocoffeae (FR691856), P. vulnus (JQ003988, FJ713007), and P. zeae (JN020935).

Real-time PCR. Real-time PCR assays were performed on a capillary-based LightCycler thermocycler (Roche Applied Science) using the FastStart DNA Master SYBR Green I dye chemistry (Roche Applied Science). Each reaction consisted of $1 \mu \mathrm{l}$ of DNA extract, $1 \mu$ of Master SYBR Green I mix, $3 \mathrm{mM} \mathrm{MgCl}_{2}$, and 5 pmol of each primer in a total volume of $10 \mu \mathrm{l}(43)$. The amplification program consisted of one initial cycle of denaturation for 10 min at $95^{\circ} \mathrm{C}$ followed by 50 cycles of $10 \mathrm{~s}$ at $95^{\circ} \mathrm{C}, 5 \mathrm{~s}$ at $66^{\circ} \mathrm{C}$, and $10 \mathrm{~s}$ at $72^{\circ} \mathrm{C}$, with fluorescence data collected after each annealing step. Melting curve profiles were generated by increasing the temperature from 60 to $95^{\circ} \mathrm{C}$ in increments of $0.1^{\circ} \mathrm{C}$ per 0.4 to 0.5 fluorescence units to visualize specific amplicons, potential primer dimers, and nonspecific amplification products. The fluorescence data were analyzed using the arithmetic baseline adjustment and second derivative maximum analysis (LightCycler Software, version 3.5). Ct number, amplification curve, and standard curve were generated from LightCycler data analysis. P. neglectus DNA from pure cultures of isolates Pn 3 and Pn4 was used as the positive control, and nanopure water and DNA from P. thornei isolate Pt1 served as negative controls. Real-time PCR assays were conducted in duplicate for each extract.

Generation of standard curves from pure culture and artificially infested soil. $P$. neglectus DNA was extracted from a total of 1,000 eggs (containing the faint outline of a developing juvenile), juveniles, and adult females (mixed stages) from carrot cultures (43). DNA $(81,000 \mathrm{pg} / \mu \mathrm{l})$ was serially diluted $(1: 1,1: 5,1: 10,1: 50$, $1: 100,1: 500$, and 1:1000) with autoclaved nanopure water. A similar dilution series was generated using an extract of Walla Walla silt loam soil that was autoclaved at $121^{\circ} \mathrm{C}, 115 \mathrm{kPa}$ for $45 \mathrm{~min}$ on two successive days. The soil was collected from a wheat field in Pendleton, OR and did not harbor detectable $P$. neglectus or $P$. thornei. Standard curves were constructed by plotting log value of DNA (picograms) against $\mathrm{Ct}$ number. Amplification efficiencies were calculated from the slopes of the plots using the equation 
provided in a previous section. PCR inhibitors could be detected by comparing $\mathrm{E}$ from serial dilutions of DNA in the soil extract to that from dilutions in water (43).

To relate $\mathrm{Ct}$ number to density of $P$. neglectus per gram of soil, a standard curve was generated from sterilized and noninfested soil by adding known numbers of nematodes. Walla Walla silt loam was passed through a 3-mm sieve and autoclaved. Half-gram samples of soil were inoculated with juveniles, adult females, and eggs (containing a faint outline of a developing juvenile) of $P$. neglectus from pure culture at five population densities (1, 5, 20, 100, and 500 per $0.5 \mathrm{~g}$ of soil). Each inoculation was done in triplicate. The soil standard curve was generated by plotting $\mathrm{Ct}$ versus $\log$ of the number of $P$. neglectus per gram of soil. The inoculations were repeated using six replicates of 0.5 nematodes, and duplicates of 1 , $5,10,20$, and 30 nematodes per $0.5 \mathrm{~g}$ of soil.

To determine whether different life stages of $P$. neglectus (juvenile, adult female, and egg) could be used in generation of the standard curves, DNA was extracted separately from an egg (containing a faint outline of a developing juvenile), a small secondstage juvenile, and an adult female in four replicates using the lysis buffer prepared in the laboratory as described in the previous section. Eggs, juveniles, and adult females were from the population of Pn4 (Moro, OR; Table 1), which was maintained in carrot cultures. Each DNA extract was assayed in duplicate qPCR reactions. $\mathrm{Ct}$ values from qPCR were expressed as mean \pm standard error of the mean.

Natural field soil samples. Soil samples were collected from 15 dryland wheat fields at eight locations in Oregon and Washington (Table 2). These field soils were naturally infested with different populations of $P$. neglectus, $P$. thornei, other plant-parasitic nematodes, and non-plant-parasitic nematodes (43). Sampling dates were during late March to late May 2008. The sampled fields varied in soil moisture status and soil type depending on location. Most samples consisted of 40 cores $(2.5 \mathrm{~cm}$ in diameter by $30 \mathrm{~cm}$ in depth) composited for each field. When soil was too dry, samples were taken by collecting from each field eight shovel slices of about $2.5 \mathrm{~cm}$ thick, $10 \mathrm{~cm}$ wide, and $10 \mathrm{~cm}$ deep. At sampling, soil was placed into large, unsealed plastic bags which were then placed over ice in an insulated cooler. The soil samples were immediately transported to our laboratory. Samples were then stored at $4^{\circ} \mathrm{C}$ at their field moisture conditions until being mixed and submitted to laboratories. Each sample was mixed thoroughly and divided into five subsamples of $600 \mathrm{~g}$ each. Four sets of subsamples were sent by overnight delivery on 30 May 2008 to four commercial and research laboratories in the PNW for nematode identification and quantification using microscopy-based procedures. The test results were reported back from laboratory (lab) 1 on 10 August, lab 2 on 23 June, lab 3 on 11 June, and lab 4 on 21 August. The fifth set of subsamples was kept at $4^{\circ} \mathrm{C}$ for 28 days, until 27 June 2008, before DNA extraction and qPCR.

Lab 1 employed the Whitehead tray extraction method for isolating nematodes from soil (41) and labs 2, 3, and 4 utilized the wetsieving and sugar-density flotation method for nematode extraction (13). Nematodes were extracted from 100 to $500 \mathrm{~g}$ of soil depending upon the protocol used by each laboratory (e.g., $200 \mathrm{~g}$ of soil by lab $1,250 \mathrm{~g}$ by lab 2, $100 \mathrm{~g}$ by lab 3 , and $500 \mathrm{~g}$ by lab 4) and converted to the number of $P$. neglectus per kilogram of soil. The total processing time at each lab for nematode identification and

Table 1. Pratylenchus spp. and other nematodes used in this study to test specificity of the quantitative polymerase chain reaction primers for Pratylenchus neglectus

\begin{tabular}{|c|c|c|c|c|}
\hline Species & Isolate & Origin & Host & Source $^{a}$ \\
\hline Pratylenchus neglectus & Pn1 & La Grande, OR & Wheat & R. Smiley \\
\hline P. neglectus & Pn2 & La Grande, OR & Wheat & R. Smiley \\
\hline P. neglectus & Pn3 & Lind, WA & Wheat & R. Smiley \\
\hline$P$. neglectus & Pn4 & Moro, OR & Wheat & R. Smiley \\
\hline P. neglectus & Pn5 & Pendleton, OR & Wheat & R. Smiley \\
\hline P. neglectus & Pn6 & Great Falls, MT & Wheat & A. Dyer \\
\hline P. neglectus & Pn7 & St Anthony, ID & Wheat & R. Smiley \\
\hline P. neglectus & Pn8 & Mission, OR & Wheat & R. Smiley \\
\hline P. thornei & Pt1 & Pendleton, OR & Wheat & R. Smiley \\
\hline P. thornei & Pt2 & Pendleton, OR & Wheat & R. Smiley \\
\hline P. thornei & Pt3 & Mission, OR & Wheat & R. Smiley \\
\hline P. agilis & 031302 & Wye, MD & Corn & A. Skantar \\
\hline P. crenatus & 012204 & Clarksville, MD & Grass & A. Skantar \\
\hline$P$. penetrans & 030402 & NY & Corn & A. Skantar \\
\hline P. penetrans & 052704 & WI & Potato & A. Skantar \\
\hline$P$. penetrans & $31 \mathrm{H} 11$ & MD & Corn & A. Skantar \\
\hline P. scribneri & 062805 & Homestead, FL & Tomato & A. Skantar \\
\hline P. scribneri & 032102 & Seneca County, $\mathrm{OH}$ & Corn & A. Skantar \\
\hline P. zeae & 030204 & $\mathrm{NC}$ & Corn & A. Skantar \\
\hline P. zeae & $22 \mathrm{G} 8$ & Singapore & Spider lily & A. Skantar \\
\hline Globodera pallida & 22D3 & ID & Potato & A. Skantar \\
\hline G. rostochiensis & $27 \mathrm{~A} 12$ & NY & Potato & A. Skantar \\
\hline G. ellingtonae & $45 \mathrm{E} 11$ & OR & Potato & A. Skantar \\
\hline G. tabacum solanacearum & $27 \mathrm{C} 3$ & Richmond, VA & Tobacco & A. Skantar \\
\hline G. tabacum tabacum & $27 \mathrm{E} 3$ & CT & Tobacco & A. Skantar \\
\hline Meloidogyne hapla & 6L6 & Canada & Rose & A. Skantar \\
\hline M. chitwoodi & $13 \mathrm{C} 8$ & OR & Potato & A. Skantar \\
\hline M. naasi & $12 \mathrm{C} 1$ & OR & Wheat & A. Skantar \\
\hline Nacobbus aberrans & 38D1 & Peru & Potato & A. Skantar \\
\hline Merlinius brevidens & $\mathrm{Mb}$ & Pendleton, OR & Wheat & G. Yan \\
\hline Heterodera avenae & Ha1 & La Grande, OR & Wheat & R. Smiley \\
\hline H. avenae & $\mathrm{Ha} 2$ & Colfax, WA & Wheat & R. Smiley \\
\hline H. avenae & $\mathrm{Ha} 3$ & St Anthony, ID & Wheat & R. Smiley \\
\hline H. filipjevi & Hf & La Grande, OR & Wheat & R. Smiley \\
\hline Non-PP community $1^{\mathrm{b}}$ & Non-PP1 & Pendleton, OR & $\ldots$ & G. Yan \\
\hline Non-PP community $2^{\text {b }}$ & Non-PP2 & Pendleton, OR & $\ldots$ & G. Yan \\
\hline
\end{tabular}

a Isolates were obtained from A. Dyer, Montana State University, Bozeman; sampled by authors R. Smiley and G. Yan; or came from the frozen nematode collection of A. Skantar.

${ }^{\mathrm{b}}$ Non-plant-parasitic (Non-PP) communities 1 and 2 were extracted from soils that were not infested with P. neglectus but were infested with many nonplant-parasitic nematodes. 
quantification varied from 12 days to 84 days (e.g., 73 days held at lab 1, 24 days at lab 2, 12 days at lab 3, and 84 days at lab 4). Storage conditions at each lab, before extractions were made, are unknown. Details of the nematode extraction protocols used by the commercial laboratories were proprietary. Species identities of $P$. neglectus and $P$. thornei in each soil sample were obtained by special request with an additional diagnostic fee. Species identity was also determined using endpoint PCR as described by Yan et al. (44). For qPCR analysis, DNA was extracted from $0.5 \mathrm{~g}$ of each of the 15 soils in triplicate. Bovine serum albumin (BSA) solution at $20 \mu \mathrm{g} / \mu \mathrm{l}$ (Roche Applied Science) was added to qPCR reaction mixtures at a final concentration of $0.4 \mu \mathrm{g} / \mu \mathrm{l}$ to reduce the effect of PCR inhibitors.

Statistical analysis. Relationships between nematode numbers from qPCR and traditional microscopy methods, between numbers of nematodes reported from four laboratories, and between $\mathrm{Ct}$ values from qPCR and nematode densities from manual counts after logarithmic transformation were determined using PROC REG of the Statistical Analysis System package (version 9.2; SAS Institute). Analysis of variance for the $\mathrm{Ct}$ values from different life stages of $P$. neglectus was performed using the general linear model (PROC GLM) in the SAS program (version 9.2).

\section{Results}

Primer design and specificity. Of the seven primer pairs (not shown) designed from the ITS regions of Pratylenchus rRNA genes, primers Pn-ITS-F2 and Pn-ITS-R2 showed specific amplification from DNA templates of all eight isolates of $P$. neglectus and produced a single peak at $83.8^{\circ} \mathrm{C}$ in melting curve analyses. The primers did not produce specific amplification from the 12 nontarget Pratylenchus or 16 other non-Pratylenchus plant-parasitic or non-plant-parasitic nematodes listed in Table 1.

The primers Pn-ITS-F2 and Pn-ITS-R2 were predicted to have strong specific annealing with the ITS sequences of six other $P$. neglectus isolates from Italy (FJ712952, FJ712955, FR692282, and FR692284), Spain (FR692297), and California (FJ717818) based on duplex stability $(\Delta \mathrm{G})$ values from in silico analysis. Specific amplification was indicated by $\Delta \mathrm{G}$ values of $-35 \mathrm{kcal} / \mathrm{mol}$ or less. The primer Pn-ITS-F2 was predicted to form a hybrid with the ITS sequence of $P$. jaehni at a $\Delta \mathrm{G}$ value of -15.1 , and Pn-ITS-R2 was predicted to hybridize with the $P$. hispaniensis sequence at a $\Delta \mathrm{G}$ value of -24.6 . Both are relatively high and, thus, predictive of unstable primer-template binding resulting in unidirectional or nonlogrithmic amplification and, hence, not competitive with specific amplification. The $P$. neglectus-primers were not predicted to result in primer-template duplexes with ITS sequences of 6 isolates of $P$. thornei from Spain (FJ713002, FJ713005, FR692299, and FR692302) and California (FJ717820 and FJ717821) and 24 other non-target isolates belonging to 22 Pratylenchus spp.

DNA extraction from soil. Inhibitors might be co-extracted from soil and interfere with qPCR. DNA of 1,000 P. neglectus from pure culture was serially diluted with water or with the soil extract of Walla Walla silt loam. The corresponding DNA concentrations were 81,000 (1:1 dilution), 16,200 (1:5), 8,100 (1:10), 1,620 (1:50), 810 (1:100), $162(1: 500)$, and $81(1: 1000) \mathrm{pg} / \mu \mathrm{l}$. The standard curve generated from $P$. neglectus DNA diluted with water was $y=-3.16 x+36.23\left(R^{2}=0.99 ; P<0.001\right)$, where $y$ is the mean $\mathrm{Ct}$ and $x$ is the log pg DNA. The slope of -3.16 indicated an $\mathrm{E}$ of 1.07 and the mean $\mathrm{Ct}$ values were 20.56 to 29.89 . The standard curve for $P$. neglectus DNA diluted with Walla Walla soil extract was $y=-3.24 x+36.32\left(R^{2}=0.98 ; P<0.001\right)$. The slope of -3.24 indicated an $\mathrm{E}$ of 1.03 and the mean $\mathrm{Ct}$ values were 20.85 to 30.52. The E of 1.03 indicated that the PowerSoil DNA Isolation Kit removed inhibitors that might have been present in the Walla Walla silt loam.

Generation and validation of a standard curve from artificially infested soils. The standard curve generated by inoculating $P$. neglectus into autoclaved, noninfested Walla Walla silt loam was $y=-3.63 x+32.69$ (Fig. 1). The soil standard curve showed an excellent $\left(R^{2}=0.96\right)$, significant $(P<0.001)$ negative relationship between $\mathrm{Ct}$ and log-transformed numbers of $P$. neglectus $(1,5,20$, 100 , and 500). The $\mathrm{Ct}$ values were 21.20 to 32.65 and $\mathrm{E}$ was 0.89 . No amplification was observed with noninoculated soil.

The soil standard curve was validated using the autoclaved Walla Walla soil inoculated with lower numbers of $P$. neglectus $(0.5,1,5$, 10,20 , and 30). There was a significant positive relationship $\left(R^{2}=\right.$ $0.79 ; P<0.001 ; y=0.895 x+1.87)$ between the numbers of $P$. neglectus added to soil and the numbers quantified using the soil standard curve (Fig. 2). Much variation was observed between the numbers from qPCR tests of replicate samples of $P$. neglectus added at 20 and 40 nematodes/g of soil (Fig. 2). As measured by the qPCR, the Ct values of $20(28.12 \pm 0.49)$ and $40(27.79 \pm 0.77)$ $P$. neglectus nematodes per gram of soil varied in a greater degree than the Ct of $1(32.15 \pm 0.20), 2(30.77 \pm 0.32), 10(28.52 \pm 0.25)$, and $60(26.28 \pm 0.11)$ P. neglectus nematodes per gram of soil.

Quantification of single nematodes at different life stages. Individuals of $P$. neglectus at different life stages (juvenile, adult female, and egg) commonly coexist in infested soil and roots or within a population derived from pure culture. Four independent DNA extracts from each of the life stages were measured by the

Table 2. Comparative quantification of Pratylenchus neglectus in natural field soils using real-time quantitative polymerase chain reaction (qPCR) or by four commercial and research laboratories (Labs 1-4) using traditional microscopic methods

\begin{tabular}{|c|c|c|c|c|c|c|}
\hline \multirow[b]{3}{*}{ Field soil } & \multirow[b]{3}{*}{ Location } & \multicolumn{5}{|c|}{ P. neglectus nematodes/kg of soil } \\
\hline & & \multirow[b]{2}{*}{ qPCR estimation ${ }^{a}$} & \multicolumn{4}{|c|}{ Microscopic estimation } \\
\hline & & & Lab 1 ${ }^{b}$ & Lab $2^{c}$ & Lab $3^{\mathbf{c}}$ & Lab $4^{c}$ \\
\hline FS1 & Lind, WA & $2,248 \pm 271$ & 689 & 493 & 110 & 0 \\
\hline $\mathrm{FS} 2$ & Lind, WA & $42,246 \pm 3,058$ & 5,385 & 5,566 & 120 & 0 \\
\hline FS3 & Lind, WA & $0 \pm 0$ & 53 & 220 & 70 & 0 \\
\hline FS4 & Ralston, WA & $0 \pm 0$ & 0 & 0 & 0 & 36 \\
\hline FS5 & Imbler, OR & $25,669 \pm 6,317$ & 4,016 & 3,460 & 100 & 5,400 \\
\hline FS6 & Union, OR & $10,076 \pm 1,774$ & 2,175 & 4,480 & 140 & 5,186 \\
\hline FS7 & Island City, OR & $15,254 \pm 6,507$ & 1,733 & 4,522 & 140 & 8,366 \\
\hline FS8 & Mission, OR & $17,374 \pm 5,298$ & 5,964 & 6,413 & 70 & 0 \\
\hline FS9 & Imbler, OR & $7,686 \pm 2,225$ & 2,182 & 1,904 & 100 & 3,146 \\
\hline FS10 & Moro, OR & $2,945 \pm 257$ & 553 & 1,240 & 120 & 0 \\
\hline FS11 & Pendleton, OR & $1,155 \pm 394$ & 974 & 442 & 20 & 0 \\
\hline FS12 & Pendleton, OR & $2,146 \pm 1,132$ & 463 & 184 & 20 & 3,182 \\
\hline FS13 & Pendleton, OR & $28,503 \pm 3,712$ & 3,700 & 8,444 & 160 & 1,936 \\
\hline FS14 & Pendleton, OR & $27,847 \pm 8,793$ & 2,156 & 3,948 & 100 & 5,234 \\
\hline FS15 & Pendleton, OR & $8,571 \pm 2,640$ & 629 & 5,520 & 10 & 6,226 \\
\hline
\end{tabular}

a Numbers of $P$. neglectus were estimated from qPCR based on the mean cycle threshold number from three independent DNA extractions, each analyzed in duplicate PCR reactions per soil sample and expressed as mean \pm standard error of the mean.

${ }^{\mathrm{b}}$ Nematode numbers reported from lab 1 using the Whitehead tray extraction, microscopic identification, and counting.

${ }^{\mathrm{c}}$ Nematode numbers reported from labs 2,3 , and 4 using the wet-sieving and sugar-density flotation methods. 
qPCR in duplicate. The resulting $\mathrm{Ct}$ values of single adult females, single small second-stage juveniles, and single eggs were $27.35 \pm$ $0.17,27.59 \pm 0.18$, and $28.16 \pm 0.42$, respectively. No significant difference $(P=0.1657)$ was observed between the $\mathrm{Ct}$ values of the three life stages, indicating that $P$. neglectus adults, juveniles, and eggs contain very similar quantities of DNA as measured by the qPCR and, therefore, mixtures of the life stages could be used to generate the standard curves from pure culture or soil.

Quantification of $P$. neglectus in naturally infested field soils. Microscopy-based nematode counts in 15 field soil samples reported from labs 1 to 4 were 0 to $5,964,0$ to $8,444,0$ to 160 , and 0 to $8,366 P$. neglectus per kilogram of soil, respectively (Table 2). The Ct values from qPCR were $26.79 \pm 0.44$ to $36.08 \pm 0.15$.

There was a significant negative regression $\left(R^{2}=0.79 ; P<\right.$ $0.001 ; y=-2.64 x+37.80$ ) between the $\mathrm{Ct}$ values from the qPCR assay and the numbers of $P$. neglectus per kilogram of soil from the Whitehead tray extraction and microscopic counting (lab 1), indicating that the two methods were in close agreement. When $\mathrm{Ct}$ values were converted to the numbers of $P$. neglectus per kilogram of soil using the soil standard curve (Fig. 1), there was a significant positive relationship $\left(R^{2}=0.66 ; P<0.001 ; y=5.54 x+1,450\right)$ between the data generated by the two methods (Table 3 ). The estimates of $P$. neglectus were generally higher using qPCR compared with the Whitehead tray method (Tables 2 and 3).

Nematode enumeration obtained using qPCR was positively correlated $\left(R^{2}=0.57 ; P<0.01\right)$ with results of lab 2 but was poorly correlated $\left(R^{2}<0.30\right)$ with counts reported by labs 3 and 4 (Table $3)$. Our analysis also revealed a significant positive correlation $\left(R^{2}\right.$ $=0.54 ; P<0.01)$ between the counts of $P$. neglectus reported by

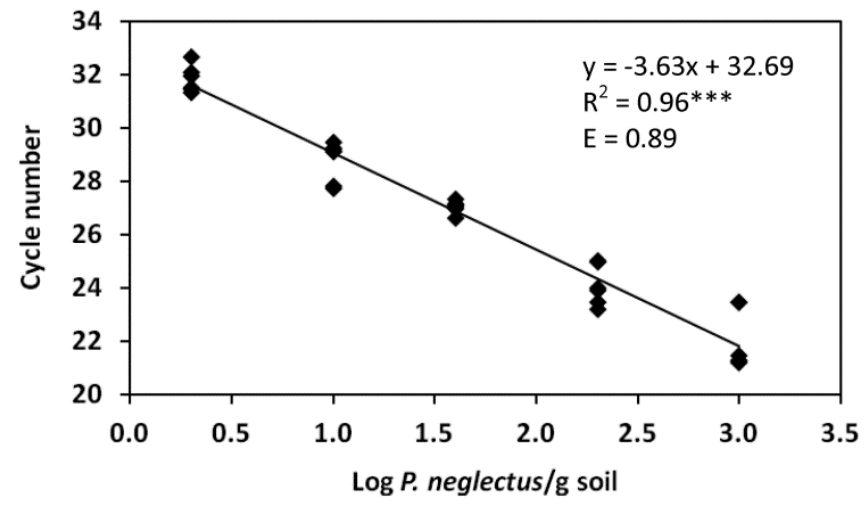

Fig. 1. Standard curve relating threshold cycle number to log of the number of Pratylenchus neglectus nematodes $(1,5,20,100$, and 500$)$ inoculated into $0.5 \mathrm{~g}$ of sterilized and noninfested soil. Each point represents three independent DNA extractions for each soil sample and duplicate quantitative polymerase chain reaction reactions. Amplification efficiency $(E)=10^{1 / \text { slope }}-1$; ${ }^{* *}$ indicates significance at $P<0.001$.

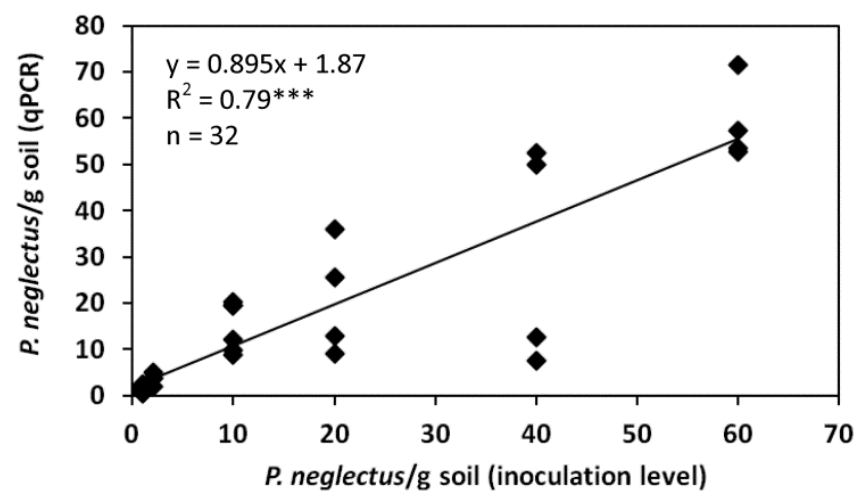

Fig. 2. Relationship between the number of Pratylenchus neglectus nematodes determined by quantitative polymerase chain reaction and the number of $P$. neglectus nematodes $(0.5,1,5,10,20$, and 30$)$ added to $0.5 \mathrm{~g}$ of sterilized and noninfested soil; ${ }^{* * *}$ indicates significance at $P<0.001$. labs 1 and 2 but not for counts from either of these laboratories with those of 3 or 4 as well as between 3 and $4\left(R^{2}<0.25\right)$ using microscopic methods (Table 3).

Real-time PCR detection sensitivity in soils. Specific amplification was obtained for populations of $P$. neglectus at as low as half of one juvenile per $0.5 \mathrm{~g}$ of soil $(\mathrm{Ct}=32.15 \pm 0.20)$. Specific amplicons were observed in each of six replicate extractions amplified in duplicate (12 assays), indicating that the qPCR can detect a single juvenile per gram of soil in $100 \%$ of the assays.

In all, 2 of the 15 natural field soil samples, FS3 and FS4, having counts of 53 and 0 nematodes $/ \mathrm{kg}$ of soil, respectively, reported from lab 1 using the Whitehead tray method (Table 2), did not produce the $P$. neglectus amplicon in melting curve analyses. The remaining samples produced specific amplification, with $\mathrm{Ct}$ values of $26.79 \pm 0.44$ to $32.46 \pm 0.76$. Sample FS12, with a relatively low population density of 463 P. neglectus nematodes per kilogram of soil, as determined by lab 1, also gave specific qPCR amplification.

\section{Discussion}

$P$. neglectus was detected and quantified directly in DNA extracts from a range of soil samples using SYBR Green I-based qPCR. This assay utilized mechanical (bead beating) and chemical disruption of nematodes provided in a commercial kit, and applied species-specific primers to rapidly detect the number of DNA copies of target nematodes for quantification. The assay was sensitive and capable of detecting genomic DNA of a single juvenile inoculated into $1 \mathrm{~g}$ of autoclaved and nematode-free soil. The assay was also highly specific, showing only a single peak in melting curve analyses using DNA of multiple isolates of target $P$. neglectus and not producing specific amplification using DNA of a variety of non-target Pratylenchus spp., other plant-parasitic nematodes, and non-plant-parasitic nematodes. To our knowledge, this is the first open-source report describing real-time PCR procedures, including primer design, DNA extraction from soil, and standard curve generation and validation, for detection and quantification of $P$. neglectus from soil.

The P. neglectus-specific primers from the $\mathrm{D} 3$ expansion domain of the 28S rRNA used in endpoint PCR $(1,44)$ lacked detection sensitivity in the qPCR format (G. Yan and R. Smiley, unpublished data). One difficulty in designing a new set of qPCR primers was the diversity among ITS sequences from different isolates of $P$. neglectus. This divergence was reported by Hafez et al. (9) for two geographically isolated populations of $P$. neglectus on potato. Thus, 14 P. neglectus DNA sequences from different geographic regions

Table 3. Relationship between the numbers of Pratylenchus neglectus determined using real-time quantitative polymerase chain reaction (qPCR) and traditional microscopic methods performed by four laboratories on natural field soils ${ }^{\mathrm{a}}$

\begin{tabular}{lccc}
\hline Relationship & $\boldsymbol{R}^{\mathbf{2}}$ & $\boldsymbol{P}$ & Equation \\
\hline qPCR vs. lab & & & \\
Lab 1 & 0.66 & 0.0002 & $y=5.54 x+1,450$ \\
Lab 2 & 0.57 & 0.0012 & $y=3.64 x+1,416$ \\
Lab 3 & 0.27 & 0.0456 & $y=132 x+1,522$ \\
Lab 4 & 0.04 & 0.4573 & $y=0.94 x+10,358$ \\
Between labs & & & \\
Lab 1 and 2 & 0.54 & 0.0018 & $y=0.521 x+417$ \\
Lab 1 and 3 & 0.19 & 0.1039 & $y=16.2 x+663$ \\
Lab 1 and 4 & 0.00 & 0.9637 & $y=-0.009 x+2067$ \\
Lab 2 and 3 & 0.24 & 0.0645 & $y=25.5 x+944$ \\
Lab 2 and 4 & 0.12 & 0.2158 & $y=0.317 x+2304$ \\
Lab 3 and 4 & 0.04 & 0.4834 & $y=0.004 x+76$ \\
\hline
\end{tabular}

${ }^{a}$ Fifteen natural field soil samples from Table 2 .

${ }^{\mathrm{b}}$ Numbers of $P$. neglectus determined by qPCR versus nematode counts from each lab; $y=\mathrm{qPCR}$ estimation and $x=$ traditional microscopic estimation

${ }^{c}$ Pairwise comparisons of numbers of $P$. neglectus from four laboratories using microscopic methods; $y$ and $x$ represent nematode counts from two different laboratories. 
in the United States and other countries were used for selecting highly conserved primers for $P$. neglectus and 8 additional isolates from Oregon, Idaho, Washington, and Montana were used for testing primer specificity. Although our findings demonstrated primer specificity for P. neglectus in the dryland wheat field soils of eastern Oregon and Washington, the genus Pratylenchus contains nearly 70 species (5). Further testing of the primers with local Pratylenchus spp. and local soils might be needed to reduce the risk of misdiagnosis when directly using DNA extracts from soil in other areas.

The sensitivity of this assay allowed accurate and consistent detection of at least 0.5 juvenile added to $0.5 \mathrm{~g}$ of autoclaved and noninfested soil, equivalent to 1,000 juveniles $/ \mathrm{kg}$ of soil. Lower proportions of a body were not tested and it is possible that sensitivity in the artificially infested soil may be even greater. The sensitivity of our P. neglectus assay was comparable with that observed from other qPCR assays. Madani et al. (16) were able to detect a single second-stage juvenile of the cyst-forming nematodes Globodera pallida and H. schachtii using qPCR with SYBR Green I dye. Sato et al. (26) could detect a single $P$. penetrans individual in a sample with an abundant number of free-living nematodes using a SYBR Green I-based qPCR method. Toyota et al. (38) sensitively detected a single second-stage juvenile of $G$. rostochiensis in mixed nematode communities of 1,000 free-living individuals. Yan et al. (43) developed a qPCR assay for P. thornei and detected one second-stage juvenile in $1 \mathrm{~g}$ of sterilized soil. The detection sensitivity of qPCR, which also detected eggs in soil, was generally higher than that of the traditional laboratory methods, which did not include eggs in soil. When higher-sensitivity qPCR tests are used, new economic damage thresholds may need to be established to make recommendations for managing P. neglectus in infested fields. Economic thresholds could be fairly variable, depending on geographic locations, climate, host tolerance, nematode virulence, and nematode extraction procedures (5). Castillo and Vovlas (5) reported the great variability of damage thresholds of $P$. thornei on wheat, which ranged from 420 to 30,000 nematodes $/ \mathrm{kg}$ of soil at various locations in Australia, France, and Mexico.

The highly precise relationship $\left(R^{2}=0.96 ; P<0.001\right)$ between $\mathrm{Ct}$ values and the log-transformed numbers of $P$. neglectus added to autoclaved soil indicated that the qPCR assay gave reliable estimates. Our soil standard curve was prepared using a range of nematode individuals inoculated into the soil but not using a dilution series of one concentrated sample containing a large number of nematodes in order to represent the variation that can be expected in natural field soils. Sato et al. (26) reported a higher variation in numbers of $P$. penetrans when introducing a range of nematode individuals into soil aliquots before extraction than using simply diluted DNA samples, likely due to variation in the extraction and purification of DNA. Berry et al. (2) constructed standard curves using different numbers of $M$. javanica, $P$. zeae, and $X$. elongatum and discussed that the estimated numbers appeared to represent the variation that could exist among replicate samples of the same number of nematodes and, thus, tended to be more representative of the variation that could occur in native samples. Furthermore, PCR inhibitors were not detected in the soil extract of autoclaved Walla Walla silt loam, which likely led to more accurate quantification of the pathogen in the artificially infested soil.

The soil standard curve was tested using the sterilized soil inoculated with lower numbers of $P$. neglectus. A significant positive relationship $\left(R^{2}=0.79 ; P<0.001\right)$ was obtained between the numbers of $P$. neglectus added to soil and the numbers quantified using the soil standard curve and qPCR. However, much variation was observed from qPCR tests of replicate samples of P. neglectus added at 20 and 40 nematodes/g of soil. This variation might arise from different amounts of DNA recovered during DNA extraction. The Ct values of 20 and 40 P. neglectus nematodes per gram of soil varied in a greater degree than four other inoculation levels. The exact reason for this variation is unknown. This might be due occasionally to the instability of the commercial kits used for DNA extraction, particularly from the vortexing step, in which nema- todes might not be disrupted evenly and completely to release DNA.

The differences between the manual counts of $P$. neglectus from the four laboratories could be due to different nematode extraction methods used. Lab 1 employed the Whitehead tray extraction method for isolating nematodes from soil and labs 2, 3, and 4 utilized the wet-sieving and sugar-density flotation method for nematode extraction. The differences could also be due to variation in storage time and conditions at each lab prior to processing, different amount of soil processed for nematode extraction, variation in specific experimental procedures and settings, degree of variation in sampling from nematode suspensions, and possible human error in counting and identification of $P$. neglectus in populations of the normal range of free-living nematode species extractable from soil, especially when many other nematode species are present. The discrepancies could also reflect the difficulty in identifying and quantifying $P$. neglectus and $P$. thornei using traditional morphological methods, given the variability among individuals between or even within populations. Therefore, commercial laboratories routinely identify and quantify Pratylenchus nematodes only to the genus level but not to the species level because of the expense and liability associated with species identification. These laboratories identified our samples to the species level upon specific request at an additional expense. Results of our comparisons among labs clearly illustrated the challenge of differentiating $P$. neglectus from $P$. thornei using traditional counting methods.

In general, qPCR tended to provide higher estimates of the numbers of $P$. neglectus compared with the Whitehead tray method, as described by the correlation equation $(y=5.54 x+1,450)$. Min et al. (17) also reported a higher density of $P$. penetrans based on qPCR compared with the Baermann method in most of their field soils. This was supported by findings of Yan et al. (43) for P. thor$n e i$ and Smiley et al. (31) for a mixed population of P. neglectus and $P$. thornei in field samples in the United States, Ophel-Keller et al. (20) for P. thornei in field samples in Australia, Toyota et al. (38) for G. rostochiensis second-stage juveniles, and Goto et al. (8) for cysts of $H$. glycines. The reason for this is that the Whitehead tray method (41) relies on the active movement of vermiform juveniles and adults from moistened soil into the surrounding water; however, eggs cannot be extracted using this method. Real-time PCR detects DNA of juveniles, adults, and eggs, which may result in estimates of higher numbers, particularly for those soil samples with higher densities of $P$. neglectus which may contain more eggs. The commercial laboratories counted adult females with visual diagnostic characters but could not identify juveniles and eggs that lack these characters. In addition, all life stages of Pratylenchus spp. are capable of surviving through very dry conditions in an inactive, dehydrated, and dormant anhydrobiotic state (5), which can be detected by qPCR but might not be easily extracted from soil by the Whitehead tray method unless dry soil is moistened during a pre-extraction period. Because eggs and vermiform nematodes in the state of anhydrobiosis are capable of recovering after prolonged periods in soil (5) and contributing to disease risk, their inclusion in nematode enumerations have risk implications to growers. It was also possible that some nematodes might be dead due to adverse conditions in the field or due to mechanical injury during soil sampling and soil mixing. Dead nematodes are certainly nonextractable by the Whitehead tray method but could be detected by qPCR if DNA of dead nematodes does not decline by $100 \%$ after a certain period of incubation in soil. Herdina et al. (11) found that $P$. thornei DNA declined by $93 \%$ after 7 days of incubation in soil and was not detectable after 14 days, indicating that DNA from dead nematodes is unlikely to cause significant overestimation of the numbers of nematodes.

The heterogeneous distribution of nematodes in soil could cause sampling errors (42-44), because DNA extraction using the PowerSoil DNA Isolation Kit was limited to $0.5 \mathrm{~g}$ of soil per extract, although this amount routinely has been used for the quantification of several plant pathogens $(3,17,18,27,43)$. Small sample volume would be especially critical for soils such as FS3 harboring very 
low densities of $P$. neglectus. Increasing the amount of soil for DNA extraction could improve the sensitivity and accuracy of the qPCR assay but would require more extractions or specialized equipment. In contrast, approximately $200 \mathrm{~g}$ of soil was routinely processed when using the Whitehead tray method. Our soils were thoroughly mixed to minimize heterogeneity. The use of more replicates of DNA extractions for each sample could reduce possible error and improve the accuracy of the assay (3). Soil moisture content and soil type could have an impact on the estimates of nematode numbers and cause higher estimations. To test whether the qPCR assay was applicable to a range of field soils, 15 soil samples were collected from different wheat fields at eight locations in Oregon and Washington. The sampled fields varied in soil moisture status and soil type depending on location. Smiley et al. (31) reported that densities of Pratylenchus spp. reported from the Root Disease Testing Service (SARDI) using a proprietary qPCR procedure were correlated $\left(R^{2}=0.70 ; P<0.01\right)$ to but generally higher than densities reported by a lab using traditional elutriationbased extractions and morphological identifications. The density of Pratylenchus spp. in one very dry field soil sample was 13 times higher from the qPCR testing than from the traditional elutriation method. Hollaway et al. (12) reported that the qPCR test using DNA extracted from soil was not affected by soil water content at the time of sampling or drying the soil after sampling. In contrast, the Whitehead tray method, which extracts mostly active nematodes, extracted fewer Pratylenchus spp. from dry soil than from moist soil and fewer from soil that had been dried before storage. The magnitudes of reduction in numbers of Pratylenchus spp. recovered from soil varied depending on soil type and differences in soil water content (31). Moreover, in soils that contain inhibitors contributing to fluorescence in qPCR assays, higher estimations might be the inhibition of PCR amplification (2). Inhibition was found in the 15 natural field soil samples (41) and, therefore, BSA was added to the qPCR reactions to reduce PCR inhibitors in the present study. A good, significant positive regression $\left(R^{2}=0.66 ; P\right.$ $<0.001$ ) was obtained between the nematode numbers determined by the two methods for these field soil samples. Other reagents that possibly reduce inhibitor activity include powdered skim milk, polyvinylpyrrolidone, and polyvinylpolypyrrolidone $(3,18,44)$.

Juveniles, adult females, and eggs of $P$. neglectus are common life stages that are present in infested soil and roots or within a population from pure culture and, thereby, mixtures of them were included in generation of the standard curves. No significant difference in the $\mathrm{Ct}$ values was found among a single adult female, a single second-stage juvenile, and a single egg from our test, indicating that different life stages of $P$. neglectus contain very similar quantities of DNA, suggesting that these life stages are eutelic. Therefore, mixtures of the life stages could be used to generate the standard curves. This finding also indicates that life stages of $P$. neglectus and proportions of juveniles, adult females, and eggs in individual samples do not affect real-time PCR detection and quantification and, therefore, are unlikely to be an explanation for the discrepancy between nematode levels measured by qPCR tests and the manual counts from laboratories. However, in the case of $P$. penetrans, Sato et al. (26) found that, in a preliminary experiment, the $\mathrm{Ct}$ values of a male $(22.7 \pm 0.7)$ and a female $(23.0 \pm 0.3)$ with larger body sizes were significantly lower $(P<0.05)$ than those from a small juvenile $(25.1 \pm 0.4)$. Therefore, the population density of $P$. penetrans but not $P$. neglectus quantified by qPCR may change depending on the composition of the life stages (male, female, and juvenile) that are present in a sample.

The qPCR assay has the capacity of simultaneously detecting and quantifying $P$. neglectus from mixed populations of Pratylenchus spp. (e.g., in the presence of $P$. thornei), from populations that might have morphological variation, and from different life stages of adults, juveniles, and eggs without limitation of nematode materials. Unlike many other publications in which DNA was extracted from nematode individuals in nematode suspensions or communities $(2,16,26,38)$, our qPCR was performed on DNA extracts from soil which allows direct quantification of $P$. neglectus from soil. The qPCR assay for $P$. neglectus provides an option for commercial laboratories to avoid time-consuming steps of traditional nematode extraction, microscopic identification, and quantification. These services will become increasingly important as Pratylenchus spp.-specific tolerant and resistant cultivars are developed and shown to be more productive in infested fields in the PNW.

\section{Acknowledgments}

This research was funded by the Idaho Wheat Commission, Oregon Wheat Commission, and Washington Wheat Commission; a cooperative agreement between Oregon State University and the United States Department of Agriculture-Agricultural Research Service (USDA-ARS) (SCA 58-5348-9-100, "Control of Root Diseases of Wheat and Barley"); and USDA-ARS Project number 5248-22000-012-00D (P. A. Okubara). We thank S. H. Hulbert and C. Yin at Washington State University for access to the NanoDrop ND-1000 Spectrophotometer, and A. Dyer for providing isolates of control nematode species.

\section{Literature Cited}

1. Al-Banna, L., Ploeg, A. T., Williamson, V. M., and Kaloshian, I. 2004. Discrimination of six Pratylenchus species using PCR and species-specific primers. J. Nematol. 36:142-146.

2. Berry, S. D., Fargette, M., Spaull, V. W., Morand, S., and Cadet, P. 2008. Detection and quantification of root-knot nematode (Meloidogyne javanica), lesion nematode (Pratylenchus zeae) and dagger nematode (Xiphinema elongatum) parasites of sugarcane using real-time PCR. Mol. Cell. Probes 22:168-176.

3. Bilodeau, G. J., Koike, S. T., Uribe, P., and Martin, F. N. 2012. Development of an assay for rapid detection and quantification of Verticillium dahliae in soil. Phytopathology 102:331-343.

4. Carrasco-Ballesteros, S., Castillo, P., Adams, B. J., and Pérez-Artés, E. 2007. Identification of Pratylenchus thornei, the cereal and legume rootlesion nematode, based on SCAR-PCR and satellite DNA. Eur. J. Plant Pathol. 118:115-125.

5. Castillo, P., and Vovlas, N. 2007. Pratylenchus, Nematoda, Pratylenchidae: diagnosis, biology, pathogenicity and management. Nematol. Monogr. Perspect. 6:1-530.

6. Filho, A. C. C., and Huang, C. S. 1989. Description of Pratylenchus pseudofallax n. sp. with a key to species of the genus Pratylenchus Filipjev, 1936 (Nematoda: Pratylenchidae). Rev. Nematol. 12:7-15.

7. Ginzinger, D. G. 2002. Gene amplification using real-time quantitative PCR: An emerging technology hits the mainstream. Exp. Hematol. 30:503-512.

8. Goto, K., Sato, E., and Toyota, K. 2009. A novel detection method for the soybean cyst nematode Heterodera glycines using soil compaction and realtime PCR. Jpn. J. Nematol. 39:1-7.

9. Hafez, S. L., Al-Rehiayani, S., Thornton, M., and Sundararaj, P. 1999. Differentiation of two geographically isolated populations of Pratylenchus neglectus based on their parasitism of potato and interaction with Verticillium dahliae. Nematropica 29:25-36.

10. Handoo, Z. A., and Golden, A. M. 1989. A key and diagnostic compendium to the species of the genus Pratylenchus Filipjev, 1936 (lesion nematodes) J. Nematol. 21:202-218

11. Herdina, Ophel-Keller, K., Wiebkin, S., Dumitrescu, I., Burns, R., and McKay, A. 2004. The detection of dead soilborne pathogens measured by a DNA-based assay. Pages 103-104 in: Proc. Third Australas. Soilborne Dis. Symp. K. Ophel-Keller, and B. Hall, eds. Department of Primary Industry and Resources South Australia, Adelaide, Australia.

12. Hollaway, G. J., Ophel-Keller, K. M., Taylor, S. P., Burns, R. A., and McKay, A. C. 2003. Effect of soil water content, sampling method and sample storage on the quantification of root-lesion nematodes (Pratylenchus spp.) by different methods. Australas. Plant Pathol. 32:73-79.

13. Jenkins, W. R. 1964. A rapid centrifugal-flotation technique for separating nematodes from soil. Plant Dis. Rep. 48:692.

14. Johnson, W. A. 2007. Discovery and distribution of root-lesion nematode, Pratylenchus neglectus, in Montana. M. S. thesis, Montana State University, Bozeman. http://etd.lib.montana.edu/etd/2007/johnson/JohnsonW1207.pdf

15. Larkin, M. A., Blackshields, G., Brown, N. P., Chenna, R., McGettigan, P. A., McWilliam, H., Valentin, F., Wallace, I. M., Wilm, A., Lopez, R., Thompson, J. D., Gibson, T. J., and Higgins, D. G. 2007. ClustalW and ClustalX version 2. Bioinformatics 23:2947-2948.

16. Madani, M., Subbotin, S. A., and Moens, M. 2005. Quantitative detection of the potato cyst nematode, Globodera pallida and the beet cyst nematode, Heterodera schachtii, using real-time PCR with SYBR Green I dye. Mol Cell. Probe 19:81-86.

17. Min, Y. Y., Toyota, K., and Sato, E. 2012. A novel nematode diagnostic method using the direct quantification of major plant-parasitic nematodes in soil by real-time PCR. Nematology 14:265-276.

18. Okubara, P. A., Schroeder, K. L., and Paulitz, T. C. 2008. Identification and quantification of Rhizoctonia solani and $R$. oryzae using real-time polymerase chain reaction. Phytopathology 98:837-847.

19. Oliveira, C. M. G., Monteiro, A. R., and Blok, V. C. 2011. Morphological and molecular diagnostics for plant-parasitic nematodes: working together 
to get the identification done. Trop. Plant Pathol. 36:65-73.

20. Ophel-Keller, K., McKay, A., Hartley, D., Herdina, and Curran, J. 2008. Development of a routine DNA-based testing service for soilborne diseases in Australia. Australas. Plant Pathol. 37:243-253.

21. Orui, Y. 1996. Discrimination of the main Pratylenchus species (Nematoda: Pratylenchidae) in Japan by PCR-RFLP analysis. Appl. Entomol. Zool. 31:505-514.

22. Qiu, J., Westerdahl, B. B., and Williamson, V. M. 2007. Detection and quantification of root-lesion nematode Pratylenchus vulnus using real-time PCR. (Abstr.) J. Nematol. 39:95.

23. Riley, I. T., Nobbs, J. M., Herdina, and McKay, A. C. 2009. Pratylenchus species in pastures in the South East Region of South Australia. Australas. Plant Dis. Notes 4:89-90.

24. Rychlik, W., and Rhoads, R. E. 1989. A computer program for choosing optimal oligonucleotides for filter hybridization, sequencing and in vitro amplification of DNA. Nucleic Acids Res. 17:8543-8552.

25. Sato, E., Goto, K., Min, Y. Y., Toyota, K., and Suzuki, C. 2010. Quantitative detection of Pratylenchus penetrans from soil using soil compaction and real-time PCR. Nematol. Res. 40:1-6.

26. Sato, E., Min, Y. Y., Shirakashi, T., Wada, S., and Toyota, K. 2007. Detection of the root-lesion nematode, Pratylenchus penetrans (Cobb), in a nematode community using real-time PCR. Jpn. J. Nematol. 37:87-92.

27. Schroeder, K. L., Okubara, P. A., Tambong, J. T., Lévesque, C. A., and Paulitz, T. C. 2006. Identification and quantification of pathogenic Pythium spp. from soils in eastern Washington using real-time polymerase chain reaction. Phytopathology 96:637-647.

28. Smiley, R. W. 2009. Root-lesion nematodes reduce yield of intolerant wheat and barley. Agron. J. 101:1322-1335.

29. Smiley, R. W. 2010. Root-lesion nematodes: biology and management in Pacific Northwest wheat cropping systems. PNW Ext. Bull. 617. Oregon State University, Corvallis.

30. Smiley, R. W., and Machado, S. 2009. Pratylenchus neglectus reduces yield of winter wheat in dryland cropping systems. Plant Dis. 93:263-271.

31. Smiley, R. W., Machado, S., Gourlie, J. A., Pritchett, L. C., Yan, G. P., and Jacobsen, E. E. 2013. Effects of crop rotations and tillage on Pratylenchus species in the semiarid Pacific Northwest USA. Plant Dis. 97:537-546.

32. Smiley, R. W., Merrifield, K., Patterson, L.-M., Whittaker, R. G., Gourlie, J. A., and Easley, S. A. 2004. Nematodes in dryland field crops in the semiarid Pacific Northwest United States. J. Nematol. 36:54-68.

33. Smiley, R. W., and Nicol, J. M. 2009. Nematodes which challenge global wheat production. Pages 171-187 in: Wheat: Science and Trade. B. F Carver, ed. Wiley-Blackwell, Ames, IA.

34. Smiley, R. W., Whittaker, R. G., Gourlie, J. A., and Easley S. A. 2005 Suppression of wheat growth and yield by Pratylenchus neglectus in the $\mathrm{Pa}$ cific Northwest. Plant Dis. 89:958-968.

35. Strausbaugh, C. A., Bradley, C. A., Koehn, A. C., and Forster, R. L. 2004 Survey of root diseases of wheat and barley in southeastern Idaho. Can. J. Plant Pathol. 26:167-176.

36. Subbotin, S. A., Ragsdale, E. J., Mullens, T., Roberts, P., and Baldwin, J. G. 2007. Molecular diagnostics and phylogenetic relationships of some species of root-lesion nematodes of the genus Pratylenchus. (Abstr.) J. Nematol. 39:80.

37. Thompson, J. P., Owen, K. J., Stirling, G. R., and Bell, M. J. 2008. Rootlesion nematodes (Pratylenchus thornei and P. neglectus): a review of recent progress in managing a significant pest of grain crops in northern Australia. Australas. Plant Pathol. 37:235-242.

38. Toyota, K., Shirakashi, T., Sato, E., and Wada, S. 2008. Development of a real-time PCR method for the potato-cyst nematode Globodera rosto chiensis and the root-knot nematode Meloidogyne incognita. Soil Sci. Plant Nutr. 54:72-76.

39. Vanstone, V. A., Hollaway, G. J., and Stirling, G. R. 2008. Managing nematode pests in the southern and western regions of the Australian cereal industry: Continuing progress in a challenging environment. Australas. Plant Pathol. 37:220-234.

40. Waeyenberge, L., Ryss, A., Moens, M., Pinochet, J., and Vrain, T. C. 2000. Molecular characterization of 18 Pratylenchus species using rDNA restriction fragment length polymorphism. Nematology 2:135-142.

41. Whitehead, A. G., and Hemming, J. R. 1965. A comparison of some quantitative methods of extracting small vermiform nematodes from soil. Ann. Appl. Biol. 55:25-38.

42. Yan, G. P., and Smiley, R. W. 2010. Distinguishing Heterodera filipjevi and $H$. avenae using polymerase chain reaction-restriction fragment length polymorphism and cyst morphology. Phytopathology 100:216-224.

43. Yan, G. P., Smiley, R. W., and Okubara, P. A. 2012. Detection and quantification of Pratylenchus thornei in DNA extracted from soil using real-time PCR. Phytopathology 102:14-22.

44. Yan, G. P., Smiley, R. W., Okubara, P. A., Skantar, A., Easley, S. A., Sheedy, J. G., and Thompson, A. L. 2008. Detection and discrimination of Pratylenchus neglectus and $P$. thornei in DNA extracts from soil. Plant Dis. 92:1480-1487. 